\title{
El rezago educativo total y su atención en México
}

\author{
The educational backwardness \\ and its attention in Mexico
}

\begin{tabular}{|c|c|}
\hline & Adrián Frausto Martín del Campo* \\
\hline $\begin{array}{l}\text { RESUMEN } \\
\text { El presente texto pretende dimensionar el rezago } \\
\text { educativo total en México y en sus estados; asimis- } \\
\text { mo se busca describir la estrategia gubernamen- } \\
\text { tal para atender dicha problemática. Por último, } \\
\text { presenta datos generales de ingreso, atención y } \\
\text { egreso de personas, hispanohablantes o hablantes } \\
\text { de lengua indígena, analfabetas, sin primaria o sin } \\
\text { secundaria. }\end{array}$ & $\begin{array}{l}\text { ABSTRACT } \\
\text { This text aims to measure the total educational } \\
\text { backwardness in Mexico and its States; also seeks } \\
\text { to describe the Government strategy to address } \\
\text { such a problem. And finally, presents general } \\
\text { information about income, care and discharge } \\
\text { of people, Spanish speakers or speakers of an in- } \\
\text { digenous language, illiterate, without primary or } \\
\text { secondary. }\end{array}$ \\
\hline $\begin{array}{l}\text { Palabras clave: Educación de adultos, rezago edu- } \\
\text { cativo, deserción, eficiencia terminal }\end{array}$ & $\begin{array}{l}\text { Keys words: adult education, educational bac- } \\
\text { kwardness, desertion, terminal efficiency }\end{array}$ \\
\hline
\end{tabular}

\section{DIMENSIÓN DEL REZAGO EN MÉXICO}

La población analfabeta ${ }^{1}$ es aquella de 15 años y más que no sabe leer ni escribir (INEA, 2015). La población sin primaria termina$\mathrm{da}^{2}$ es la población alfabeta sin primaria terminada de 15 años y más, que sabiendo leer y escribir no inició o no concluyó la educación primaria y no es atendida por el sistema escolarizado de educación básica (INEA, 2015). A su vez, la población sin

\footnotetext{
${ }^{1}$ Se calcula a partir de la población analfabeta correspondiente al 31 de diciembre de 2009, y cada año se incorporan a esta los jóvenes analfabetas que cumplen 15 años, así como la población que pierde la habilidad de la lectoescritura, y se elimina el número de personas de 15 años y más que se alfabetiza, la población analfabeta que fallece o migra y la continuidad educativa (INEA, 2015).

${ }^{2}$ Se calcula a partir de la población alfabeta sin primaria terminada correspondiente al 31 de diciembre de 2009 y cada año se incorporan a esta tanto población de 15 años y más que deserta del sistema escolarizado de educación primaria, como aquella en el mismo rango de edad que se alfabetiza, y se elimina el número de personas de 15 años y más que concluyen la educación primaria, la población sin primaria que fallece o migra; además, se le resta los analfabetas de retorno y suma la continuidad educativa (INEA, 2015).
}

"Centro de Estudios Educativos; adrian.frausto@cee.edu.mx 
secundaria terminada ${ }^{3}$ es la población de 15 años y más, que teniendo la primaria concluida, no inició o no concluyó la educación secundaria y no es atendida por el sistema escolarizado de educación básica (INEA, 2015).

La tendencia histórica de las tasas de personas en situación de rezago educativo total contrasta con los datos absolutos de las poblaciones. El cuadro 1 muestra que el porcentaje se ha reducido drásticamente, por ejemplo, en el dato de personas con rezago de $87.1 \%$ a $35 \%$ en los últimos $45 \%$; sin embargo, en números absolutos se ha incrementado el número, pues lo que cambió fue la base poblacional, que ha aumentado considerablemente en las últimas décadas.

\section{CUADRO 1. Histórico de rezago educativo en México}

\begin{tabular}{|l|c|c|c|c|c|c|c|c|c|}
\hline Año & $\begin{array}{c}\text { Población } \\
\text { de 15años } \\
\text { omás }\end{array}$ & Analfabetas & $\%$ & $\begin{array}{c}\text { Sin primaria } \\
\text { terminada }\end{array}$ & $\%$ & $\begin{array}{c}\text { Sin } \\
\text { secundaria } \\
\text { terminada }\end{array}$ & $\%$ & Rezago total & $\%$ \\
\hline 1970 & 25938558 & 6693706 & $25.8 \%$ & 11063021 & $42.7 \%$ & 4822789 & $18.6 \%$ & 22579516 & $87.1 \%$ \\
\hline 1980 & 37927410 & 6451740 & $17.0 \%$ & 9442220 & $24.9 \%$ & 9202459 & $24.3 \%$ & 25096419 & $66.2 \%$ \\
\hline 1990 & 49610876 & 6161662 & $12.4 \%$ & 11642527 & $23.5 \%$ & 11921824 & $24.0 \%$ & 29726013 & $59.9 \%$ \\
\hline 2000 & 62842638 & 5942091 & $9.5 \%$ & 11716715 & $18.6 \%$ & 14898655 & $23.7 \%$ & 32557461 & $51.8 \%$ \\
\hline 2010 & 78423336 & 5393665 & $6.9 \%$ & 10082386 & $12.9 \%$ & 16424106 & $20.9 \%$ & 31900157 & $40.7 \%$ \\
\hline 2015 & 86692412 & 4749057 & $5.5 \%$ & 9468441 & $10.9 \%$ & 16113744 & $18.6 \%$ & 30331242 & $35.0 \%$ \\
\hline
\end{tabular}

Fuente: Elaboración propia con base en INEA, 2015.

Hoy en día, las entidades federativas tienen al menos 20\% de rezago total entre su población de 15 años y más. Los estados con mayor porcentaje de este indicador son Chiapas, Oaxaca, Michoacán, Guerrero y Veracruz. Además, estas mismas entidades se encuentran también entre las diez con mayor proporción de personas de 15 ańos y más analfabetas, sin primaria y sin secundaria terminadas. Las entidades con menor proporción de población en situación de rezago educativo son la CDMX, Nuevo León, Sonora, Coahuila y Quintana Roo.

\footnotetext{
${ }^{3}$ Se calcula a partir de la población sin secundaria terminada correspondiente al 31 de diciembre de 2009, y cada año se incorpora a esta los jóvenes que desertan del sistema escolarizado de educación secundaria y la población que egresa de primaria y no ingresa al sistema escolarizado de educación secundaria, asì como los adultos que terminan primaria, se elimina el número de personas de 15 años y más que concluye la educación secundaria y la población que fallece o migra (INEA, 2015).
} 
EL REZAGO EDUCATIVO TOTAL Y SU ATENCIÓN EN MÉXICO

CUADR0 2. Rezago educativo en México, 2015

\begin{tabular}{|c|c|c|c|c|c|c|c|c|c|}
\hline \multirow[b]{2}{*}{ Entidad Federativa } & \multirow[b]{2}{*}{$\begin{array}{c}\text { Población de } 15 \\
\text { años y más }\end{array}$} & \multicolumn{2}{|c|}{ Rezago total } & \multicolumn{2}{|c|}{ Analfabetas } & \multicolumn{2}{|c|}{$\begin{array}{c}\text { Sin primaria } \\
\text { terminada }\end{array}$} & \multicolumn{2}{|c|}{$\begin{array}{l}\text { Sin secundaria } \\
\text { terminada }\end{array}$} \\
\hline & & $\%$ & Lugar & $\%$ & Lugar & $\%$ & Lugar & $\%$ & Lugar \\
\hline Nacional & 88154689 & 34.1 & & 5.0 & & 10.9 & & 18.2 & \\
\hline Chiapas & 3604589 & 51.4 & 1 & 14.3 & 1 & 16.4 & 2 & 20.7 & 5 \\
\hline Oахаса & 2831787 & 48.6 & 2 & 12.3 & 3 & 15.5 & 4 & 20.8 & 4 \\
\hline Michoacán & 3295877 & 47.5 & 3 & 7.5 & 6 & 17.1 & 1 & 22.9 & 1 \\
\hline Guerrero & 2480074 & 46.6 & 4 & 12.5 & 2 & 14.2 & 6 & 19.9 & 7 \\
\hline Veracruz & 5945578 & 43.8 & 5 & 8.7 & 4 & 15.8 & 3 & 19.3 & 8 \\
\hline Puebla & 4381897 & 42.3 & 6 & 7.7 & 5 & 13 & 8 & 21.6 & 2 \\
\hline Guanajuato & 4140983 & 40 & 7 & 5.9 & 10 & 12.7 & 9 & 21.4 & 3 \\
\hline Zacatecas & 1125450 & 37.3 & 8 & 3.6 & 17 & 14.9 & 5 & 18.8 & 11 \\
\hline Yucatán & 1567728 & 37.2 & 9 & 6.9 & 8 & 13.6 & 7 & 16.7 & 22 \\
\hline San Luis Potosí & 1969210 & 35.1 & 10 & 5.7 & 11 & 12.4 & 11 & 17 & 20 \\
\hline Jalisco & 5762549 & 35 & 11 & 3.4 & 21 & 11.2 & 15 & 20.4 & 6 \\
\hline Hidalgo & 2078471 & 34.4 & 12 & 7.5 & 6 & 9.8 & 20 & 17.1 & 19 \\
\hline Campeche & 665095 & 33.7 & 13 & 6.2 & 9 & 11.6 & 14 & 15.9 & 26 \\
\hline Sinaloa & 2195036 & 33.5 & 14 & 4 & 15 & 12.5 & 10 & 17 & 20 \\
\hline Nayarit & 884744 & 32.5 & 15 & 4.8 & 13 & 12 & 12 & 15.7 & 27 \\
\hline Colima & 537519 & 32.3 & 16 & 3.5 & 18 & 11.2 & 15 & 17.6 & 16 \\
\hline Tabasco & 1724298 & 32.3 & 16 & 5.2 & 12 & 11.7 & 13 & 15.4 & 28 \\
\hline Durango & 1268767 & 32.1 & 18 & 2.9 & 23 & 10.5 & 17 & 18.7 & 12 \\
\hline Morelos & 1416549 & 31.3 & 19 & 4.5 & 14 & 10.2 & 19 & 16.6 & 24 \\
\hline Tamaulipas & 2619734 & 31.3 & 19 & 2.6 & 24 & 10.4 & 18 & 18.3 & 14 \\
\hline Tlaxcala & 912029 & 31.2 & 21 & 3.5 & 18 & 8.6 & 25 & 19.1 & 10 \\
\hline Chihuahua & 2686680 & 31.1 & 22 & 2.3 & 25 & 9.6 & 21 & 19.2 & 9 \\
\hline Querétaro & 1452960 & 30 & 23 & 3.8 & 16 & 8.5 & 26 & 17.7 & 15 \\
\hline México & 12365632 & 29 & 24 & 3 & 22 & 8.4 & 27 & 17.6 & 16 \\
\hline Baja California & 2580704 & 28.9 & 25 & 1.8 & 30 & 8.4 & 27 & 18.7 & 12 \\
\hline Aguascalientes & 915028 & 28 & 26 & 2 & 26 & 9.4 & 22 & 16.6 & 24 \\
\hline BCS & 562132 & 27.9 & 27 & 2 & 26 & 9.2 & 23 & 16.7 & 22 \\
\hline Quintana Roo & 1145394 & 27 & 28 & 3.5 & 18 & 9.2 & 23 & 14.3 & 31 \\
\hline Coahuila & 2165652 & 26.1 & 29 & 1.9 & 29 & 6.8 & 30 & 17.4 & 18 \\
\hline Sonora & 2141795 & 25.3 & 30 & 2 & 26 & 8.3 & 29 & 15 & 30 \\
\hline Nuevo León & 3794535 & 23.4 & 31 & 1.5 & 31 & 6.6 & 31 & 15.3 & 29 \\
\hline CDMX & 6936213 & 20.1 & 32 & 1.4 & 32 & 5.1 & 32 & 13.6 & 32 \\
\hline
\end{tabular}

Fuente: Elaboración propia con base en INEA, 2015. 
Por distribución etaria quinquenal, la población de 15 años y más con mayor rezago educativo total es la correspondiente al grupo de 65 años o más, siendo las mujeres el subgrupo con mayor índice respecto a los hombres. Es de llamar la atención que a menor edad la proporción de población en rezago total disminuye hasta el grupo de 20 a 24 años, y vuelve a aumentar en el grupo de 15 a 19 años. La tendencia del índice en el que el grupo de las mujeres es mayor que los hombres se mantiene hasta el grupo de 30 a 34 años, en grupos de menor edad se revierte la situación.

GRÁFICA 1. Rezago quinquenal y por género, 2015

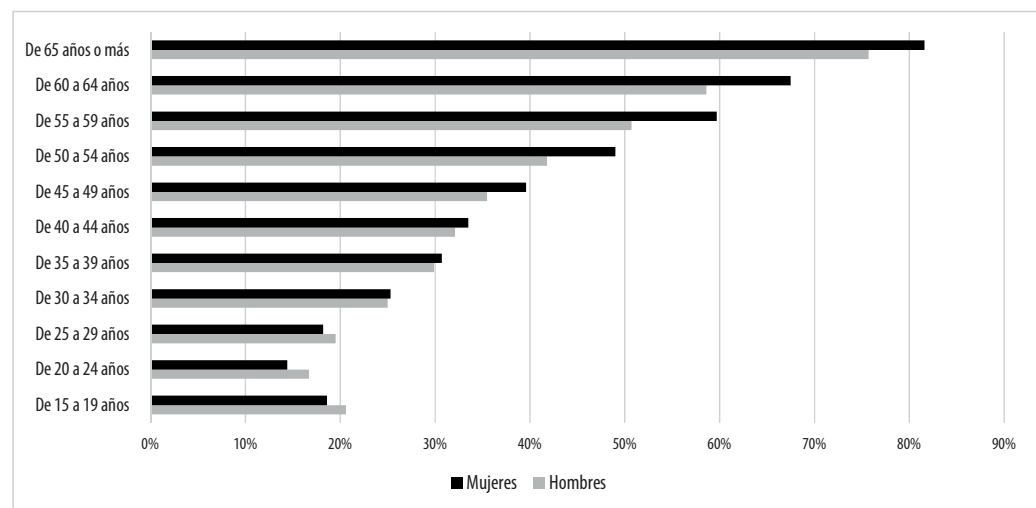

Fuente: Elaboración propia con base en INEA, 2015.

En la gráfica 2 se observa que el rezago educativo total en población urbana ha disminuido casi exponencialmente de los grupos quinquenales de mayor edad a los menores para 2015. De los grupos de 30 a 34 años a 65 o más la tasa de mujeres supera a la de hombres. Situación que se invierte en los grupos de menor edad a estos. 
GRÁFICA 2. Rezago educativo urbano, 2015

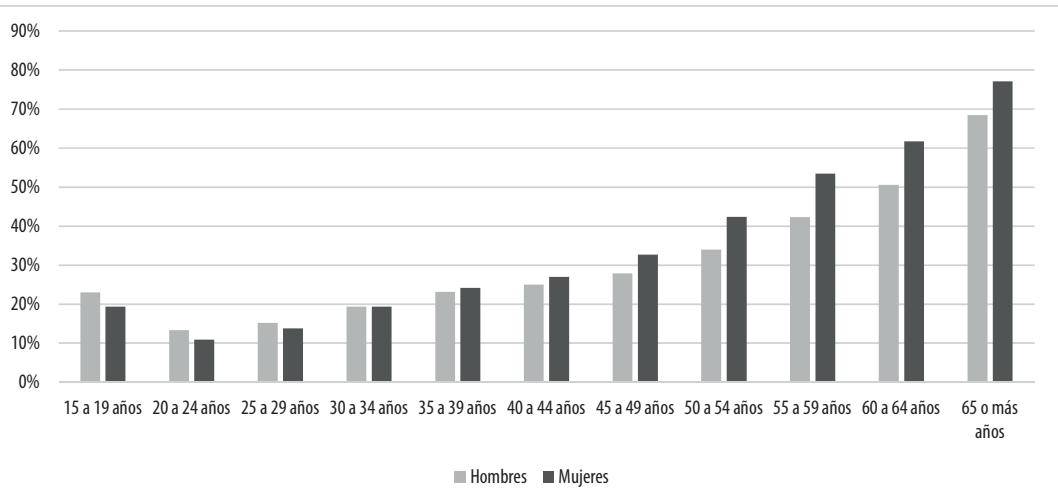

Fuente: Elaboración propia con base en INEA, 2015.

En la gráfica 3 se muestra que en la población rural el rezago total en sectores urbanos también se reduce de grupos de mayor edad a los de menos; sin embargo, el declive es menor de un grupo a otro, en comparación con la población urbana. Se observa también que la brecha entre hombres y mujeres es menor que en los centros urbanos, aunque sigue siendo mayor la tasa de mujeres en grupos de 30 años o más.

GRÁFICA 3. Rezago educativo rural, 2015

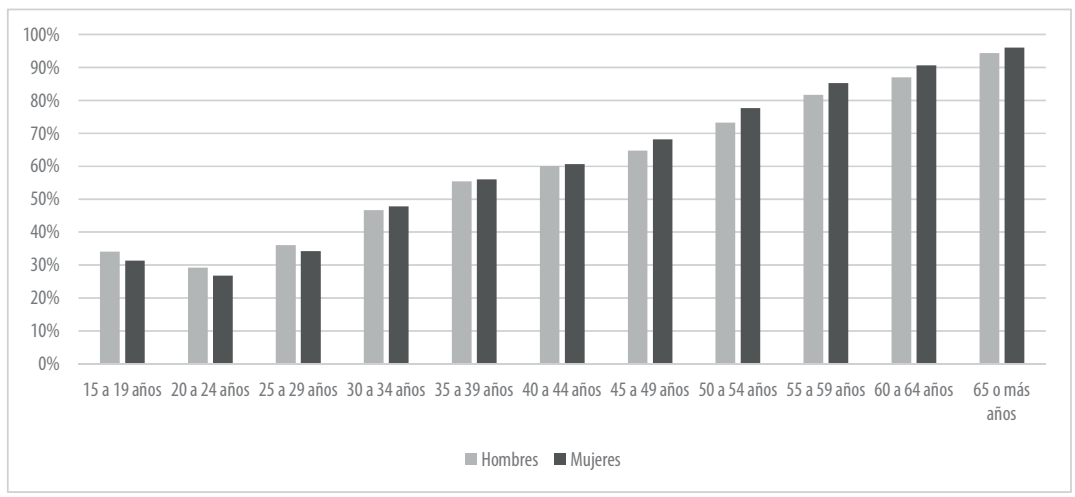

Fuente: Elaboración propia con base en INEA, 2015. 
La situación de rezago educativo total es mayor si la población es hablante de alguna lengua indígena. Más de $80 \%$ de las entidades federativas tienen una tasa de $50 \%$ o más de este indicador, llegando hasta más de $70 \%$ de la población de 15 años o más, como el caso de Chihuahua, Guerrero, Puebla, Chiapas, Veracruz y Oaxaca.

GRÁFICA 4. Rezago educativo estatal de hablantes indígenas, 2015

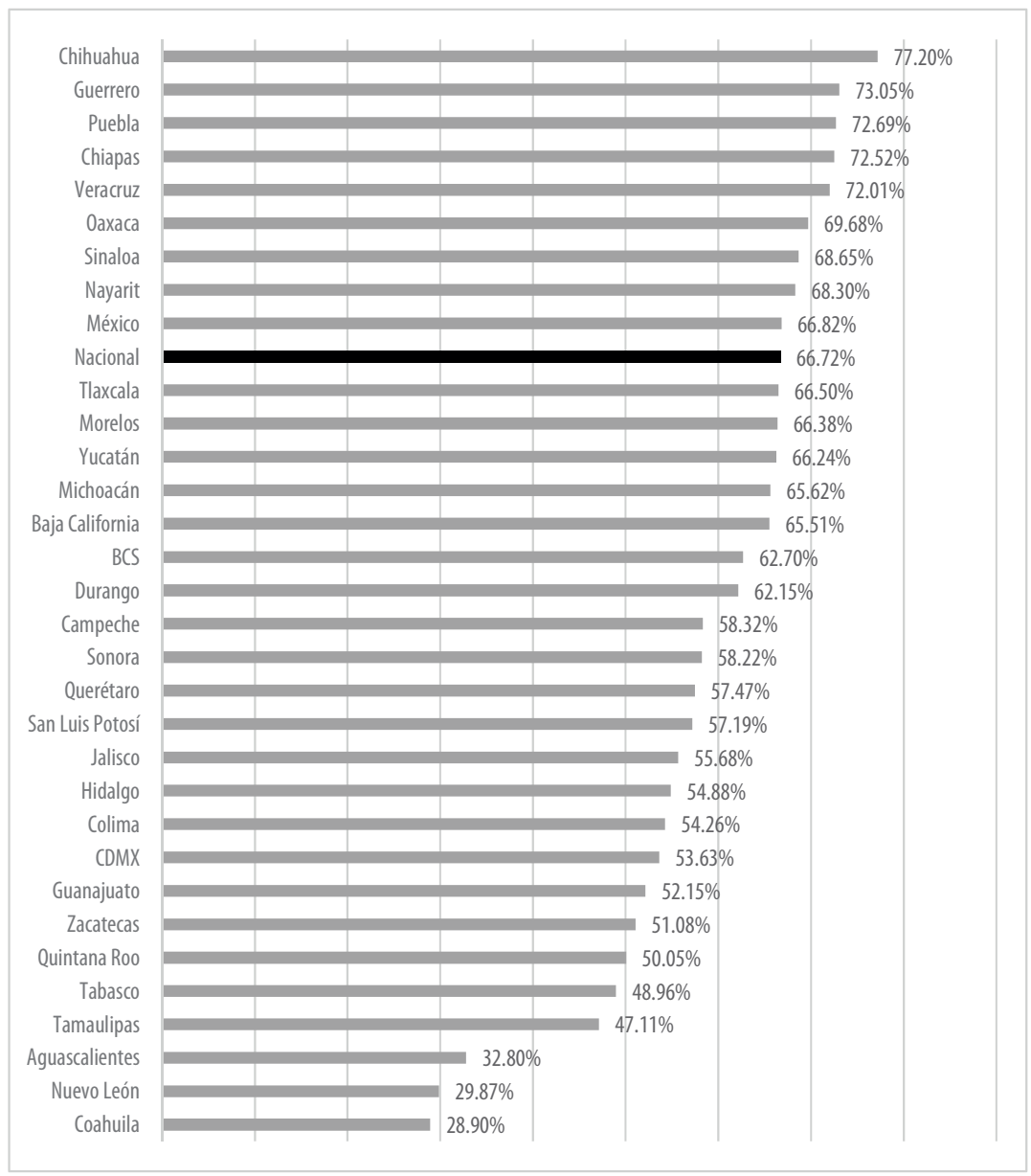

Fuente: Elaboración propia con base en INEA, 2015. 
Por otra parte, hay una alta correlación entre el desarrollo de las personas y el grado de rezago educativo. El Índice de Desarrollo Humano (IDH) permite medir dimensiones indispensables para el desarrollo de las personas: la posibilidad de gozar salud y una vida larga, el acceso a recursos necesarios para tener una vida digna, y acceso a educación (PNUD, 2015). La gráfica 5 muestra la regresión lineal del rezago educativo estatal con el IDH de cada entidad federativa. Se observa que la tendencia general es prácticamente una línea, es decir a menor IDH, mayor porcentaje de rezago educativo en población de 15 años o más.

GRÁFICA 5. Rezago educativo estatal, 2015 vs IDH estatal, 2012

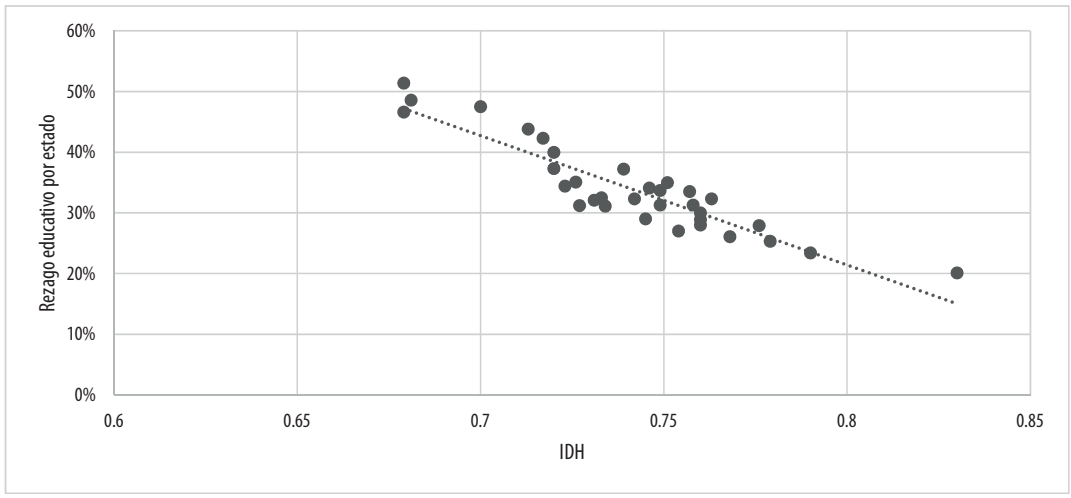

Fuente: Elaboración propia con base en PNUD, 2015 e INEA, 2015.

\section{LA ATENCIÓN DEL REZAGO EDUCATIVO EN EL PAÍS}

La atención a la población con rezago educativo en México es atendida por el Estado con base en la Constitución. El Artículo 3o establece lo siguiente:

Toda persona tiene derecho a recibir educación. El Estado -federación, estados, ciudad de México y municipios-, impartirá educación preescolar, primaria, secundaria y media superior. La educación preescolar, primaria y secundaria conforman la educación básica; esta y la media superior serán obligatorias (Constitución Política de los Estados Unidos Mexicanos, 1917). 
La Ley General de Educación (LGE) establece, en su artículo trigésimo noveno, que dentro del sistema educativo nacional está la educación para adultos (Congreso de los EUM, 1993). En su artículo 43 se determina que la educación para adultos está destinada a individuos de quince años o más que no hayan cursado o concluido la educación primaria y secundaria y, para atender a esta población, se darán servicios de alfabetización, educación primaria y secundaria, así como de formación para el trabajo, con las particularidades adecuadas a dicha población. Y por último, en el artículo 44 de la misma ley, se explicita que la educación para adultos corresponde de manera exclusiva a las autoridades locales, sin excluir del todo a la autoridad educativa federal.

\section{EL INSTITUTO NACIONAL PARA LA EDUCACIÓN DE LOS ADULTOS (INEA)}

El INEA se creó el 28 de agosto de 1981 por decreto presidencial. Dicho instituto se erigió con el objetivo de promover, organizar e impartir educación para adultos, en tanto organismo descentralizado de la Administración Pública Federal, con personalidad jurídica y patrimonio propios (SEP, 2012).

Fue hasta 2005 cuando, a través del Acuerdo Secretarial 363, se estableció el Modelo de Educación para la Vida y el Trabajo $(\mathrm{MEVyT})$, el cual tiene como propósito fundamental ofrecer a las personas jóvenes y adultas de 15 años o más, opciones educativas vinculadas con sus necesidades e intereses, orientadas a desarrollar sus competencias para desenvolverse en mejores condiciones en su vida personal, familiar, laboral y social (SEP, 2012).

En la presente administración federal, la educación para adultos está contenida en la estrategia 3.2.1 del objetivo 3.2: ampliar las oportunidades de acceso a la educación en todas las regiones y sectores de la población, cuya línea de acción es la de fortalecer los servicios que presta el INEA (Gobierno de la República, 2013).

En el Plan Sectorial de Educación (PSE) se resalta que la educación de los adultos debe tener entre sus propósitos la disminución del rezago, pero también el de fomentar el aprendizaje a lo largo de la vida. Además, se reconoce que los adultos en condición de rezago educativo han adquirido saberes prácticos y 
posiblemente se han beneficiado de la capacitación en el trabajo; por tanto, la formación de los adultos debe reconocer este tipo de aprendizajes y combinarlos con aspectos académicos (SEP, 2013).

De esta forma, el INEA está a cargo de la coordinación, con la mayoría de los gobiernos estatales, de la descentralización de los servicios de educación para adultos, por lo que el Instituto se asume como un organismo técnico, normativo y rector de la educación para adultos que acredita la educación básica proporcionada por los Institutos Estatales de Educación para Adultos (IEEA), y así fungir como promotor de este beneficio entre los diferentes sectores sociales (INEA, 2017). Sin embargo, hoy en día, el INEA (2017) continúa proporcionando algunos servicios en los estados en los que aún no se concluye el proceso de descentralización.

El Instituto cuenta con un presupuesto promedio de casi dos millones de pesos por año desde 2007; la participación en el presupuesto total anual del ramo administrativo 11 ha variado de $0.8 \%$ a $1.2 \%$ para el periodo $2007-2017$. El ańo que dispuso de mayor presupuesto fue 2015 , justo cuando tuvo una variación de casi $40 \%$ más respecto al año anterior (véase gráfica 6). Más adelante se observará que, en este mismo año, se registró un aumento considerable de ingreso en alfabetización y el MEVyT.

CUADR0 3. Presupuesto INEA precios constantes (base 2008), 2007-2017

\begin{tabular}{|l|c|c|}
\hline Año & Monto anual & $\begin{array}{c}\text { Participación en } \\
\text { el Ramo 11 }\end{array}$ \\
\hline 2007 & $\$ 1928172939$ & $1.2 \%$ \\
\hline 2008 & $\$ 1819009577$ & $1.0 \%$ \\
\hline 2009 & $\$ 2024303440$ & $1.0 \%$ \\
\hline 2010 & $\$ 1722380086$ & $0.9 \%$ \\
\hline 2011 & $\$ 1837049866$ & $0.9 \%$ \\
\hline 2012 & $\$ 1952285174$ & $0.9 \%$ \\
\hline 2013 & $\$ 1891468397$ & $0.9 \%$ \\
\hline 2014 & $\$ 1807528233$ & $0.8 \%$ \\
\hline 2015 & $\$ 2470086686$ & $1.0 \%$ \\
\hline 2016 & $\$ 2460060662$ & $1.1 \%$ \\
\hline 2017 & $\$ 1764703553$ & $0.9 \%$ \\
\hline
\end{tabular}

Fuente: Elaboración propia con base en SHCP , 2017. 
REVISTA LATINOAMERICANA DE ESTUDIOS EDUCATIVOS, VOL. XLVII, NÚM. 2, 2017

GRÁFICA 6. Variación Presupuesto INEA y Ramo 11 (precios constantes 2008), 2008-2017

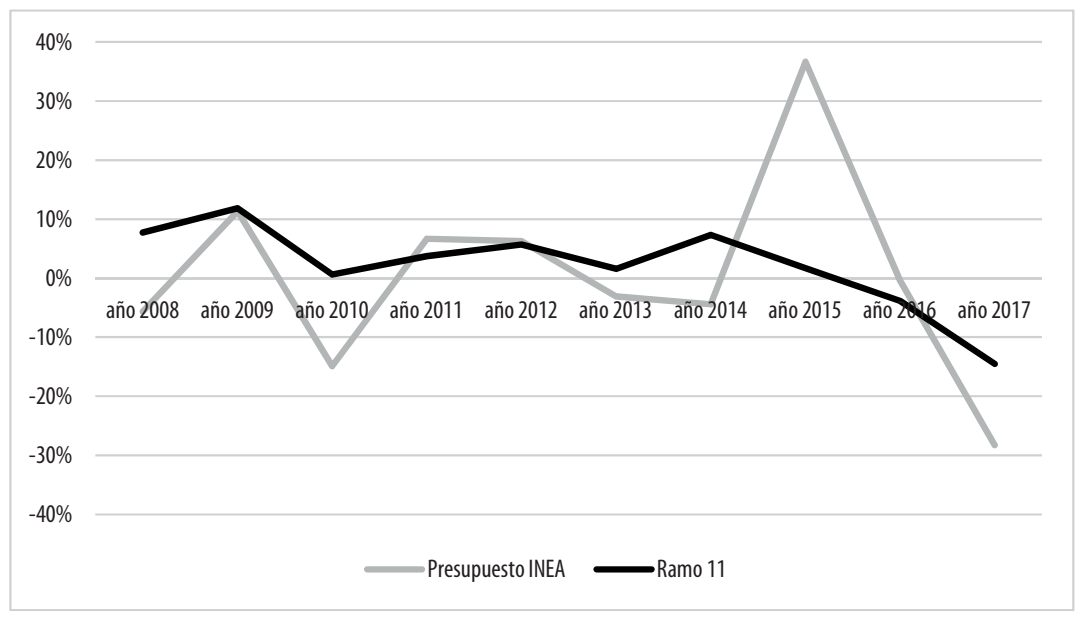

Fuente: Elaboración propia con base en SHCP , 2017.

\section{El Modelo Educativo para la Vida y el Trabajo (MEVyT)}

El MEVyT es el modelo educativo del INEA, que a su vez es una alternativa para la alfabetización, primaria y secundaria para personas en situación de rezago educativo. Según el Instituto, el modelo tiene las siguientes características:

- Visión centrada en el aprendizaje y en la persona que aprende.

- Tiene una estructura modular.

- Se adapta a tiempos, ritmos y disponibilidad de espacios.

- Adopta contenidos, metodologías y actividades adecuadas a jóvenes y adultos.

- Recupera saberes y experiencias personales y colectivas para construir otros aprendizajes y desarrollar habilidades, actitudes y valores.

- Variedad de temas de estudios optativos.

- Permite la vinculación entre los niveles de educación básica. 
El MEVyT está compuesto por tres niveles (INEA, 2017): Inicial, Intermedio y Avanzado. La primaria corresponde a los niveles inicial e intermedio, mientras que el avanzado comprende el nivel de secundaria. El nivel inicial está compuesto por módulos básicos, mientras que los niveles intermedio y avanzado disponen, además de módulos básicos, de módulos diversificados.

\section{El Programa Especial de Certificación (PEC)}

El PEC es una estrategia de la Secretaría de Educación Pública que, a través del INEA, certifica los conocimientos adquiridos por experiencia laboral. El PEC está basado en el MEVyT y está enfocado hacia aquellas personas mayores de 15 años que no terminaron primaria o secundaria, pero siguieron formándose en su trabajo, en su oficio o en otros espacios, y puedan certificar su aprendizaje. La persona interesada tiene que seguir los siguientes pasos para obtener su certificación:

1. Presenta una autoevaluación, sobre valores cívicos y el desempeño ciudadano.

2. Comprueba la experiencia mediante la presentación de reconocimientos y constancias que demuestren que ha tomado cursos de capacitación. $\mathrm{O}$ que los recibió como beneficiario de programas sociales como son Prospera, 65 y más; en el Seguro Popular o en la Comisión Nacional para el Desarrollo de los Pueblos Indígenas.

3. Presenta, con el apoyo del INEA, una evaluación de conocimientos básicos en lengua y comunicación, ciencia y matemáticas.

\section{ATENCIÓN DEL REZAGO EDUCATIVO EN CIFRAS}

Para el tema de la alfabetización de personas mayores de 15 años, el INEA reporta el promedio mensual de educandos atendidos, el ingreso y egreso, ambos anuales, a partir de septiembre de 2014.

Se observa que, de los ańos comparados, la mayor tasa de personas atendidas fue en 2015, tanto para hablantes de español como para los de lengua materna indígena. La población hispa- 
nohablante atendida supera en seis veces a la población de habla indígena.

En cuanto al ingreso anual, las cifras de 2015 son casi 2.5 veces mayores que las del año posterior. La misma situación de superioridad de volumen ocurre en el número de graduados en alfabetización en 2015 respecto de 2016, pero en una relación uno a uno un cuarto.

CUADR0 4. Datos de atención, ingreso y egreso en Alfabetización, 2014-2016

\begin{tabular}{|l|l|r|r|c|}
\hline \multicolumn{5}{|l|}{ Alfabetización } \\
\hline \multirow{4}{*}{ Educandos atendidos (promedio mensual) } & & $2014^{*}$ & 2015 & 2016 \\
\hline \multirow{5}{*}{ Ingreso anual } & Hispanohablante & 224292 & 300459 & 257026 \\
\cline { 2 - 5 } & Indígena & 41058 & 51597 & 41406 \\
\cline { 2 - 5 } & Total & 265350 & 352056 & 298432 \\
\hline \multirow{3}{*}{ Egreso (graduados) nacional anual } & Hispanohablante & 111938 & 418274 & 171423 \\
\cline { 2 - 5 } & Indígena & 7800 & 40403 & 18116 \\
\cline { 2 - 5 } & Total & 119738 & 458677 & 189539 \\
\hline & Hispanohablante & 119615 & 305316 & 239745 \\
\cline { 2 - 5 } & Indígena & 9374 & 26133 & 25570 \\
\cline { 2 - 5 } & Total & $184351^{* *}$ & 331449 & 265315 \\
\hline
\end{tabular}

Fuente: Elaboración propia con base en INEA, 2017.

* El registro inició en septiembre de ese año.

** Dato reportado, pero no coincide con la de egreso hispanohablante e indígena.

Respecto a los datos disponibles de personas atendidas por el MEVyT, se observa que ha ingresado un promedio de 1500000 aproximadamente por ańo; siendo 2015 el ańo en que más registros se reportan y 2016 el ańo en que menos.

CUADR0 5. Ingreso anual en el MEVyT hispanohablantes, 2011-2016

\begin{tabular}{|l|c|c|c|c|c|c|}
\hline & 2011 & 2012 & 2013 & 2014 & 2015 & 2016 \\
\hline Inscripción educandos & 1774952 & 1430137 & 1385874 & 1719488 & 1727072 & 1088439 \\
\hline
\end{tabular}

Fuente: Elaboración propia con base en INEA, 2017. 
En cuanto al promedio mensual de los educandos hispanohablantes atendidos con el MEVyT, se observa en la gráfica 7 que hay una disminución considerable en el dato de 2015 respecto a los ańos anteriores, mientras que hay un crecimiento sostenido del promedio en nivel inicial a partir de 2013.

GRÁFICA 7. Educandos atendidos MEVyT hispanohablantes (promedio mensual), 2011-2016

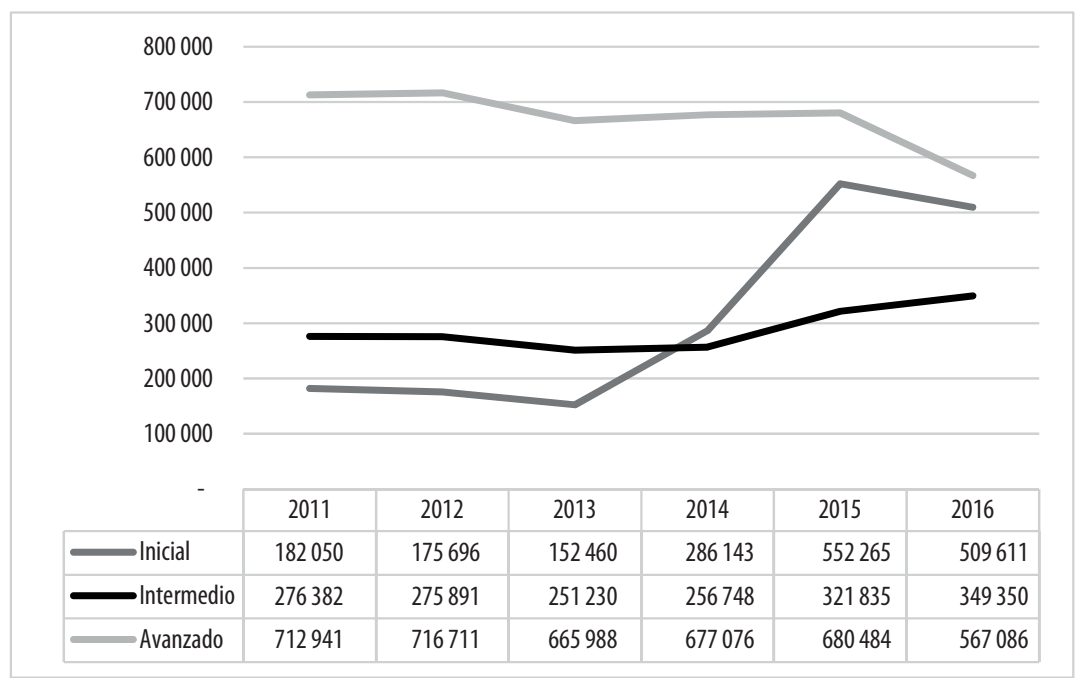

Fuente: Elaboración propia con base en INEA, 2017.

Por su parte, el dato nacional del número de personas graduadas fue superior en el nivel avanzado, respecto a los otros, lo que significa que el mayor volumen se concentra en estudiantes que terminaron o estaban cursando la secundaria. Se observa, también, que se mantuvo constante el egreso entre los años 2011 y 2014 para los tres niveles, pero se registró un aumento en 2015 en el nivel inicial, mientras que para ese mismo año decreció el nivel avanzado. 
REVISTA LATINOAMERICANA DE ESTUDIOS EDUCATIVOS, VOL. XLVII, NÚM. 2, 2017

GRÁFICA 8. Egreso (Graduados) MEVyT hispanohablantes Nacional, 2011-2016

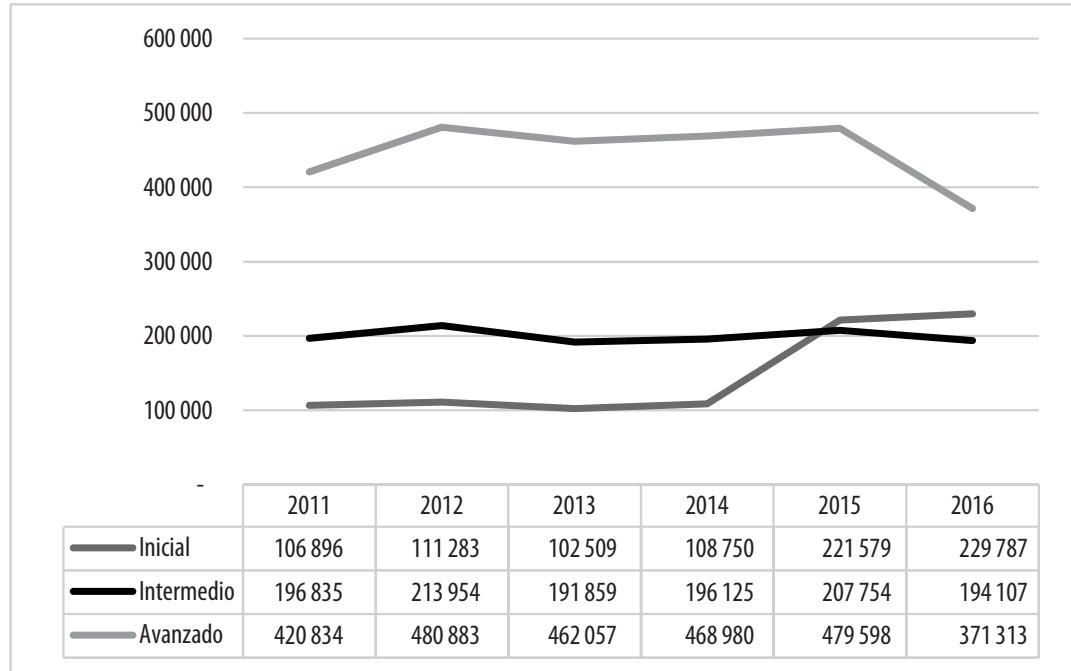

Fuente: Elaboración propia con base en INEA, 2017.

Cabe recordar que una gran proporción de indígenas está en situación de rezago educativo, por tanto, la atención a este sector es primordial. De 2011 a 2015 se duplicó el número de personas que ingresaron a algún nivel del modelo. Aunque para 2015 el número de registros disminuyó en 2016, la tendencia es positiva en estos años.

CUADRO 6. Datos de ingreso en el MEVyT indígenas, 2011-2016

\begin{tabular}{|l|c|c|c|c|c|c|}
\hline & 2011 & 2012 & 2013 & 2014 & 2015 & 2016 \\
\hline Inscripción educandos & 43439 & 45805 & 55250 & 73313 & 88235 & 77067 \\
\hline
\end{tabular}

Fuente: Elaboración propia con base en INEA, 2017.

El mayor volumen de educandos atendidos de 2011 a 2016 se encuentra, en promedio, en el nivel inicial. Muy por debajo de esos datos, las personas atendidas en el nivel intermedio y avanzado. Sin embargo, la tendencia de registros es a la alza al pasar de los ańos, presentando un crecimiento sostenido el nivel intermedio (primaria). Esto es de llamar la atención, porque la gráfica 
representa que el servicio requerido por la población indígena es básico, en contraste con la población hispanohablante, cuyos datos se ubican en el nivel avanzado.

GRÁFICA 9. Educandos atendidos MEVyT indígenas (promedio mensual), 2011-2016

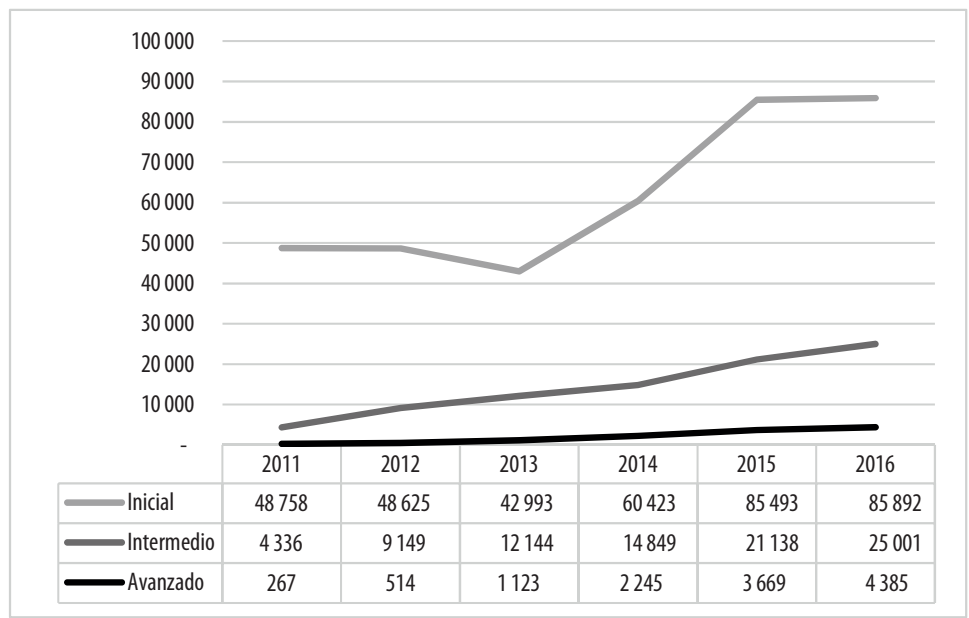

Fuente: Elaboración propia con base en INEA, 2017.

El número nacional de egresados es mayor para el nivel inicial, lo cual es congruente con el promedio nacional de educandos atendidos. Llama la atención que el ingreso sea considerablemente mayor al egreso; desafortunadamente, el INEA no presenta indicadores de abandono o eficiencia terminal, para tener una idea del grado de deserción entre niveles. 
REVISTA LATINOAMERICANA DE ESTUDIOS EDUCATIVOS, VOL. XLVII, NÚM. 2, 2017

GRÁFICA 10. Egreso (graduados) MEVyT indígenas nacional, 2011-2016

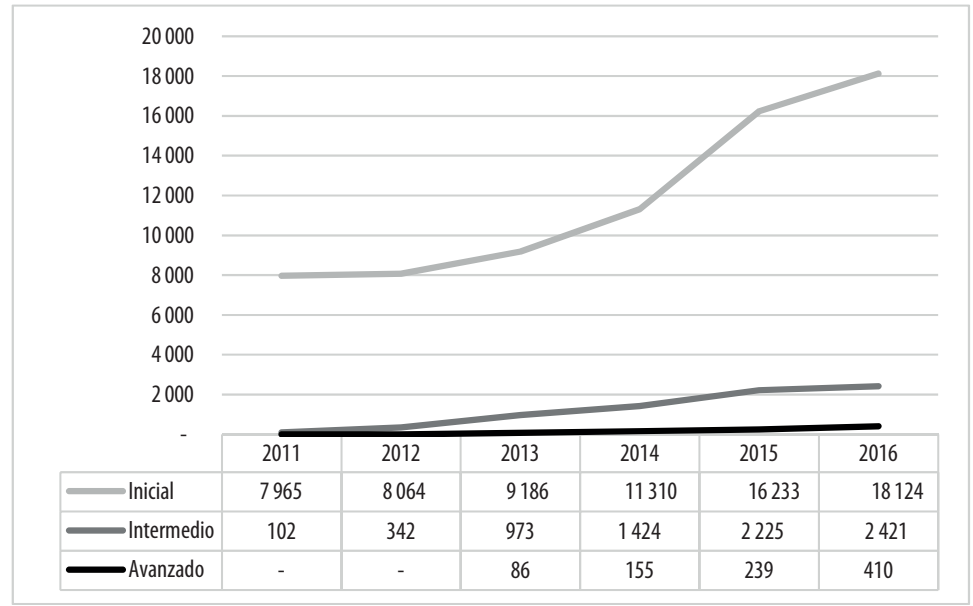

Fuente: Elaboración propia con base en INEA, 2017.

Por último, de los registros obtenidos de la página del INEA, solo se obtuvo información del número de egresados del PEC en 2016. Tales datos superan en casi el doble a los egresados por el MEVyT en el mismo año.

\section{CUADR0 7. Egreso nacional anual PEC, 2016}

\begin{tabular}{|l|l|}
\hline Inicial & - \\
\hline Intermedio & 632194 \\
\hline Avanzado & 641308 \\
\hline TOTAL & 1273502 \\
\hline
\end{tabular}

Fuente: Elaboración propia con base en INEA, 2017.

\section{CONSIDERACIONES FINALES}

- La atención a las personas en situación de rezago educativo, ha sido, y sigue siendo una cuenta pendiente para las autori- 
dades educativas. No se puede soslayar esta problemática, ni se puede pretender erradicar esta situación con paliativos.

- La información disponible en torno al rezago educativo total, en cuanto estadísticas e indicadores, no permite dimensionar ni caracterizar la atención que el Estado brinda a las personas de 15 años o más que no saben leer ni escribir, o que no tienen la primaria o secundaria concluidas. Es necesario contar con indicadores como eficiencia terminal, absorción, abandono, tasa de terminación, etcétera.

- Se destaca que el aumento del presupuesto del INEA para 2015 se reflejó también en el registro de personas atendidas y de ingreso, sobre todo para el nivel básico del MEVyT. Ahora bien, será importante que el incremento en el ingreso se traduzca en una mayor permanencia y mayor eficiencia terminal de las personas incorporadas.

- La presente entrega da muestra de la dimensión tanto del rezago educativo en nuestro país, como de la atención por parte del gobierno a este grupo, y también se delinean algunos recursos (modelo educativo y recursos financieros) con los que cuenta el INEA para la atención. Nunca fue la intención agotar el tema, sino continuar el diálogo en torno a otros temas relacionados con la educación para adultos, tales como: la pertinencia del modelo educativo, el impacto de este en el desarrollo profesional de las personas y de las comunidades donde viven, la evaluación institucional y de programas, etcétera.

\section{REFERENCIAS BIBLIOGRÀFICAS}

Congreso de los EUM. Ley General de Educación, 1993.

Constitución Política de los Estados Unidos Mexicanos, 1917.

Gobierno de la República. Plan Nacional de Desarrollo 20132018, México, 2013. Disponible en http://www.gob.mx/ cms/uploads/attachment/file/123650/PND.pdf.

INEA. México, 2015. Disponible en http://www.inea.gob.mx/ transparencia/pdf/Metodologia_rezago_educativo_ act_2015.pdf 
INEA. ¿QQué hacemos?, México, 2017. Disponible en http://www. gob.mx/inea/que-hacemos

INEA. INEA en números, México, 27 de Junio de 2017. Disponible en INEA en números: http://www.inea.gob.mx/ineanum/

INEA. MEVyT ¿Cómo está organizado?, México, 2017. Disponible en http://www.cursosinea.conevyt.org.mx/recursos/ promo_mevyt/Con_frames/principal.html

PNUD. Índice de Desarrollo Humano para las Entidades Federativas, México, 2015. Disponible en http://www. mx.undp.org/content/dam/mexico/docs/Publicaciones/ PublicacionesReduccionPobreza/InformesDesarrolloHumano/PNUD_boletinIDH.pdf

SEP. Decreto por el que se reforma el diverso por el que se crea el Instituto Nacional para la Educación de los Adultos, publicado el 31 de agosto de 1981, México, 23 de Agosto de 2012.

SEP. Programa Sectorial de Educación 2013-2018, México, 2013. Disponible en http://www.gob.mx/cms/uploads/ attachment/file/123652/Programa-sectorial-de-educacion-2013-2018.pdf

SHCP. Paquete económico y presupuestos. Presupuesto de egresos de la federación, México, 2017. Disponible en http:// finanzaspublicas.hacienda.gob.mx/es/Finanzas_Publicas/ Paquete_Economico_y_Presupuesto 